\title{
Thoraco-laparoscopic Ivor-Lewis esophagectomy: the most extensive Indian experience
}

\author{
Ramkrishnan Parthasarathi, GHV Raghvendra Gupta, Sandeep C. Sabnis, Palanivelu Praveen Raj, \\ Palanisamy Senthilnathan, Subbiah Rajapandian, Chinnusamy Palanivelu
}

Department of Gastrointestinal and Minimal Access Surgery, GEM Hospital and Research Centre, Ramanathapuram, Coimbatore 641045, Tamil Nadu, India.

Correspondence to: Dr. Ramkrishnan Parthasarathi, Department of Gastrointestinal and Minimal Access Surgery GEM Hospital and Research Centre 45, Pankaja Mills Road, Ramanathapuram, Coimbatore 641045, Tamil Nadu, India.

E-mail: drparthu@geminstitute.in

How to cite this article: Parthasarathi R, Gupta GR, Sabnis SC, Raj PP, Senthilnathan P, Rajapandian S, Palanivelu C. Thoracolaparoscopic Ivor-Lewis esophagectomy: the most extensive Indian experience. Mini-invasive Surg 2019;3:20.

http://dx.doi.org/10.20517/2574-1225.2019.10

Received: 20 Mar 2019 First Decision: 17 Jun 2019 Revised: 27 Jun 2019 Accepted: 10 Jul 2019 Published: 20 Jul 2019

Science Editor: Tetsu Fukunaga Copy Editor: Jia-Jia Meng Production Editor: Jing Yu

\begin{abstract}
Aim: The overall incidence of adenocarcinoma is on the rise, mainly in the western population. Minimally invasive thoracolaparoscopic esophagectomy for adenocarcinoma of gastroesophageal junction tumors is being adopted worldwide, albeit with a slower pace. This study is to share our experience and technical modifications over two decades.
\end{abstract}

Methods: This a retrospective data from 2009-2018 at a single center, including all the 143 cases of thoracolaparoscopic Ivor Lewis esophagectomies performed. There were no exclusions. The study objectives were to evaluate postoperative recovery, complications, and pathological completeness.

Results: In 11 years, we have performed 532 cases of minimally invasive esophagectomies for both malignant and benign etiologies. Out of which 143 cases were of Ivor Lewis esophagectomy. The mean age of patients was $64.4 \pm$ 10.86 years, and male to female ratio is 3:1. Out of these cases, 139 (97.20\%) were performed for malignancy and 4 (2.79\%) for benign cases, which include peptic stricture, sigmoid esophagus. The mean operative time is $457.97 \pm$ $79.35 \mathrm{~min}$. The mean blood loss was $138.08 \pm 29.3 \mathrm{~mL}$. Out of these cases, the hand-sewn anastomosis was performed in $72(50.34 \%)$, circular stapler anastomosis in $46(32.16 \%)$ and, linear stapled anastomosis in $25(17.48 \%)$. The mean lymph node retrieval rate was $22.68 \pm 9.49$ nodes. The average ICU stay in the postoperative period was 4.68 \pm 3.95 days, and overall hospital stay was $13.48 \pm 7.43$ days. Among malignant cases (139), adenocarcinoma in 121

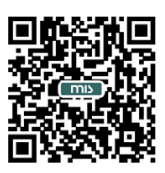


(87.05\%), squamous cell carcinoma in 18 (12.94\%). Among these cases T2, lesions in 56 (40.28\%), T3 lesions in 77 (55.39\%), T4 lesions in 6 (4.31\%) The overall complication rate was $12.58 \%$ (pneumonia- $8.39 \%$, RLN injury in $1.39 \%$, anastomotic leak in $2.09 \%$, chyle leak in $0.69 \%$, anastomotic stricture in $12.58 \%$ ). 3 (2.09\%) cases had re-intervention in the form of combined endoscopic procedures (stenting) and re-thoracoscopic lavage in 3. Overall 30 -day mortality in 1 case $(0.69 \%)$.

Conclusion: Thoracolaparoscopic esophagectomy with intrathoracic Ivor Lewis anastomosis is an excellent option for selected patients, in experienced hands.

Keywords: Ivor Lewis esophagectomy, thoracolaparoscopic, carcinoma esophagus, adenocarcinoma esophagus, intrathoracic anastomosis, minimally invasive surgery

\section{INTRODUCTION}

Worldwide, an estimated 572,034 new esophageal cancer cases and 508,585 deaths are expected annually, according to data from the GLOBOCAN database ${ }^{[1]}$. Over the last decade, the incidence of squamous cell carcinoma (SCC) has declined, and the rate of adenocarcinoma of the esophagus, esophagogastric junction (EGJ) and gastric cardia is on raise $\mathrm{e}^{[2,3]}$.

Various minimally invasive approaches that include trans-hiatal, McKeown's, and Ivor Lewis are increasingly being used given a significant reduction in the pulmonary morbidity involved with their open counterparts. For adenocarcinoma of the distal esophagus and EGJ lesions, proximal gastrectomy with subtotal esophagectomy and intrathoracic anastomosis or total gastrectomy with lower mediastinal lymph node dissection is the surgical treatment ${ }^{[4]}$. Ivor Lewis esophagectomy (ILE) including thoracotomy and laparotomy ${ }^{[5]}$ was the commonly performed surgery and now minimally invasive ILE including thoracoscopy and laparoscopy, has gained popularity ${ }^{[6]}$. The main obstacles for widespread use of minimally invasive surgery are the adequacy of esophageal resection margin and complete radical lymphadenectomy with minimal morbidity. These challenges can be addressed by improvement in techniques throughout the learning curve.

Till now very few centers are regularly performing minimally invasive ILE worldwide and to our knowledge, this is possibly most extensive series from India.

\section{METHODS}

This is a retrospective study of a prospectively maintained database of all consecutive patients who have undergone minimally invasive thoracolaparoscopic esophagectomy at a quaternary care teaching hospital from 2009 to 2018 .

The primary objective of this study is to access the outcomes of the said procedure, mainly in terms of postoperative recovery, complications, and pathological completeness. There are no exclusions during this period.

The records of demographic details, investigations, perioperative data, and complications, if any were retrieved into a proforma. The pathological reports along with followup details too, were added.

All patients with suspected esophageal malignant lesion underwent routine pre-operative blood investigations, ultrasonography of the abdomen, along with esophagogastroduodenoscopy. Contrastenhanced computerized tomography scan of the abdomen and chest were done unless there was a high 


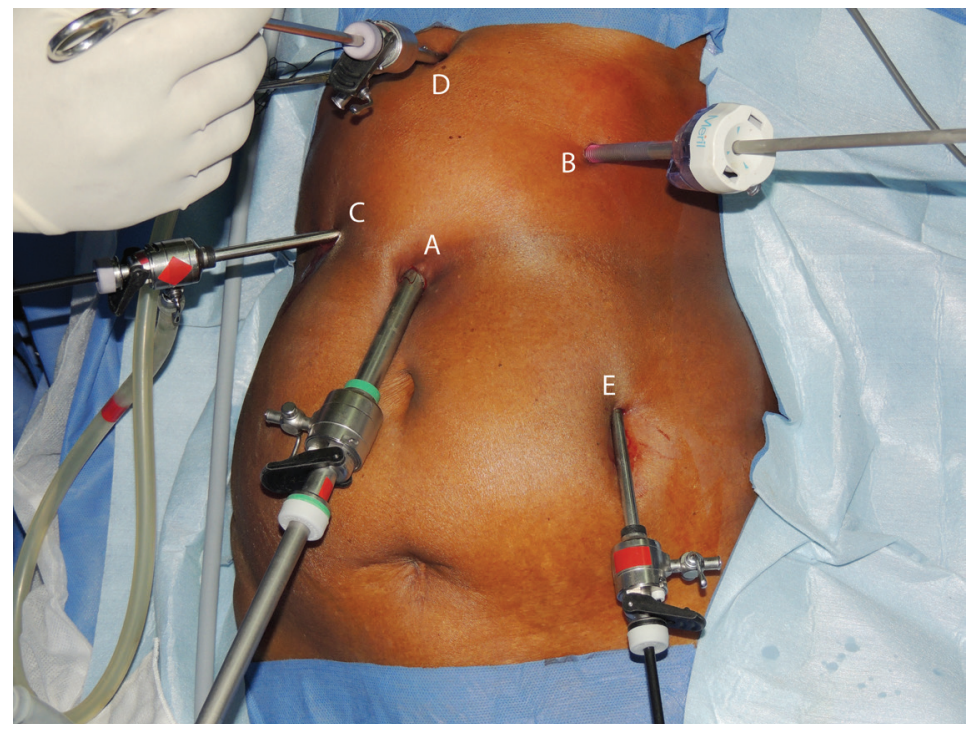

Figure 1. Port position for abdominal phase. A: Supraumbilical port for camera: $10 \mathrm{~mm}$; B: Left midclavicular for right hand working port: $5 \mathrm{~mm}$; C: Right midclavicular for left hand working port: $5 \mathrm{~mm}$ (converted to $12 \mathrm{~mm}$ for gastric conduit formation); D: Epigastric port for liver retraction $5 \mathrm{~mm}$; E: Left anterior axillary port for gastric retraction: $5 \mathrm{~mm}$ (converted to $12 \mathrm{~mm}$ for dividing Transhiatally)

index of suspicion for metastatic disease. In all T3 and T4 patients, neoadjuvant chemotherapy was given both for adenocarcinoma and SCC. At discharge, patients were advised for follow up after seven days, three months, and 1-year post-surgery and once in a year after that. Patients received adjuvant treatment based on their final pathology reports, as well as following a preoperative treatment plan.

Data were expressed in mean/median for continuous variables, while categorical variables were shown as frequencies. SPSS Version 24 (IBM Corp. NY, US) was used to analyze the data. A P-value of less than 0.05 was considered statistically significant.

\section{Two-stage esophagogastrectomy}

\section{Stage I: Abdominal phase}

General anesthesia is induced with a single lumen endotracheal tube using double lung ventilation. The patient is positioned in the reverse Trendelenburg position for laparoscopic abdominal step. Gastric mobilization and formation of the gastric conduit are done in the first phase. Port positions: Figure 1.

Gastric mobilization: The gastrocolic omentum is divided between the stomach and transverse colon, preserving the right gastroepiploic arterial arcade and up to the first part of the duodenum. Further, proximal dissection of the stomach is done by dividing the short gastric vessels using harmonic shears. Gastric fundus is dissected carefully from the superior pole of the spleen. The attachment between the posterior wall of the stomach and pancreas is divided, and all adhesions are freed using harmonic shears.

Lymph node clearance: The gastrohepatic omentum is divided close to the liver [Figure 2]. Here, care is taken to preserve the right gastric arterial arcade. The lesser omentum is separated further and left gastric pedicle is exposed. Left gastric artery and vein dissected and clipped and divided. Lymphofatty tissues over the celiac axis, left gastric pedicle, hepatic artery and splenic artery (stations 7,8,9,11p) are dissected and skeletonized to achieve complete nodal clearance. During this dissection, the stomach is retracted anteriorly and laterally. $11 \mathrm{~d}$ (distal splenic) nodes are dissected out. 


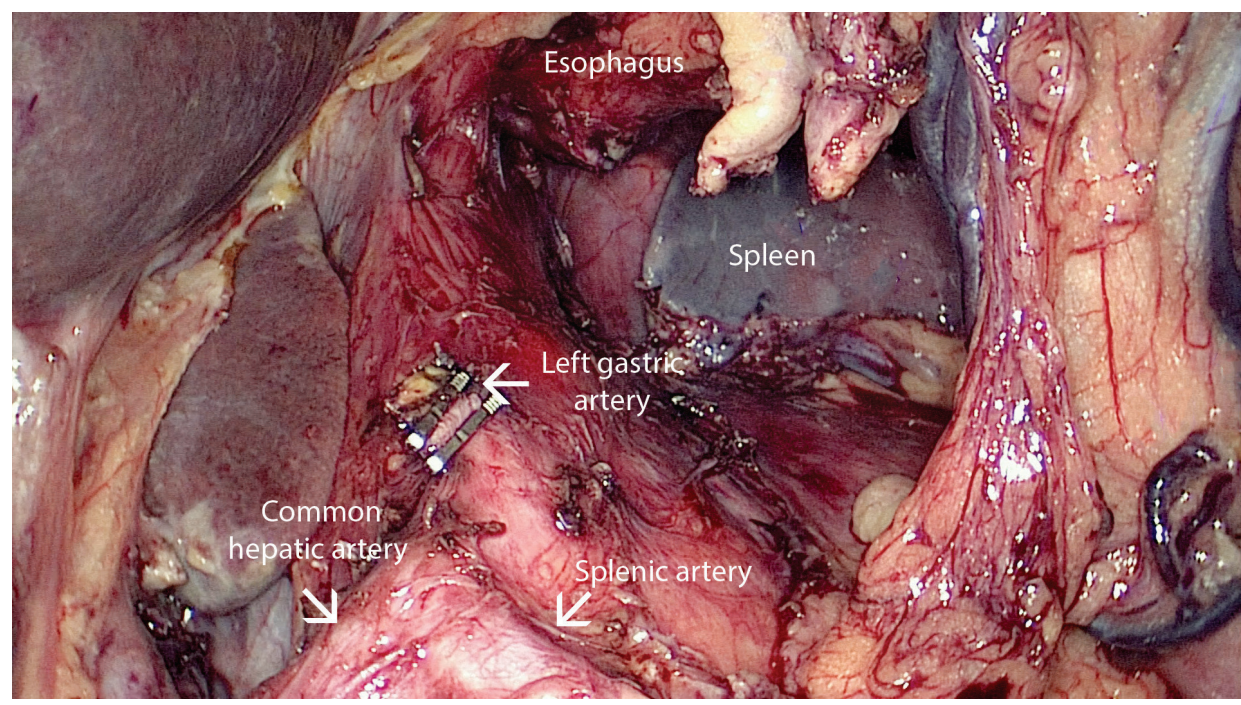

Figure 2. Laparoscopic view after D2 lymph node clearance

\begin{abstract}
Abdominal Esophageal mobilization: The abdominal esophagus is separated from the right crus, and anteriorly it is freed by dividing the phrenoesophageal membrane. Right and left paracardial lymph nodes (station 1,2) dissected. The esophagus is lifted, posterior dissection is carried out, and attachment to the left crus is divided. Anterior border of the hiatus and/or left crus are divided obliquely toward the left side using harmonic shears. Sometimes, the division of the right crus may also be needed to facilitate dissection into the posterior mediastinum. Then liver retractor is advanced into the mediastinum for retraction. These two maneuvers expose the mediastinum. Dissection is carried out in the mediastinum carefully without injuring the pleura.
\end{abstract}

Trans hiatal mobilization of the thoracic esophagus: The esophagus is then retracted above and laterally [Figure 3]. Intrathoracic esophageal dissection to be started on the right side by separating right mediastinal pleura from the esophagus. The esophagus is lifted high with the left-hand instrument, and posterior attachment to preaortic fascia over the aorta is carefully dissected and divided using harmonic scalpel/vessel sealing device. Simultaneously, a complete lymph nodal dissection is performed in the posterior mediastinum with removing the lymph nodes with $5 \mathrm{~mm}$ harmonic shears. The esophagus is retracted to the right side and attachment of the left mediastinal pleura from mesoesophagus (Fibrofatty tissue with small blood vessels to the esophagus from the aorta) is dissected out. Lastly, anteriorly esophagus is separated from the pericardium. This dissection can be carried up to 6-7 $\mathrm{cm}$ above the hiatal level.

Gastric conduit creation: Gastric conduit is formed by firing a $60 \mathrm{~mm}$ endo GIA gold cartridge stapler (๑) Ethicon US, LLC) perpendicularly and 2-3 subsequent firing of blue cartridge staplers obliquely [Figure 4]. The liver retractor is passed into mediastinum above the right crus and pericardium well lifted above. After esophageal dissection, using a flexible, and curved stapler passed through left side intrathoracically, the esophagus is divided, making sure, the transection line is above the tumor [Figure 5]. A small opening formed in the right pleura and the gastric conduit is placed within in the right pleural cavity [Figure 6].

Through a Pfannenstiel incision, the specimen is removed out. In cases of smaller lesions, the stomach is not entirely divided and is pulled up in the intrathoracic phase and removed through a small thoracic incision. 


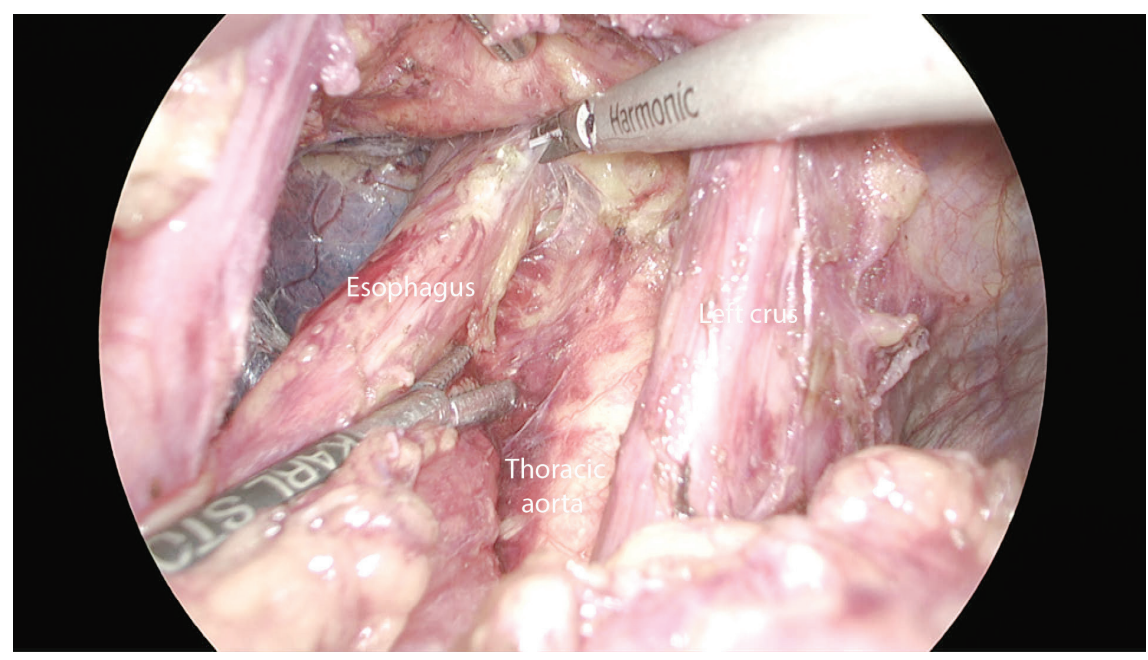

Figure 3. Laparoscopic view of trans hiatal mobilization

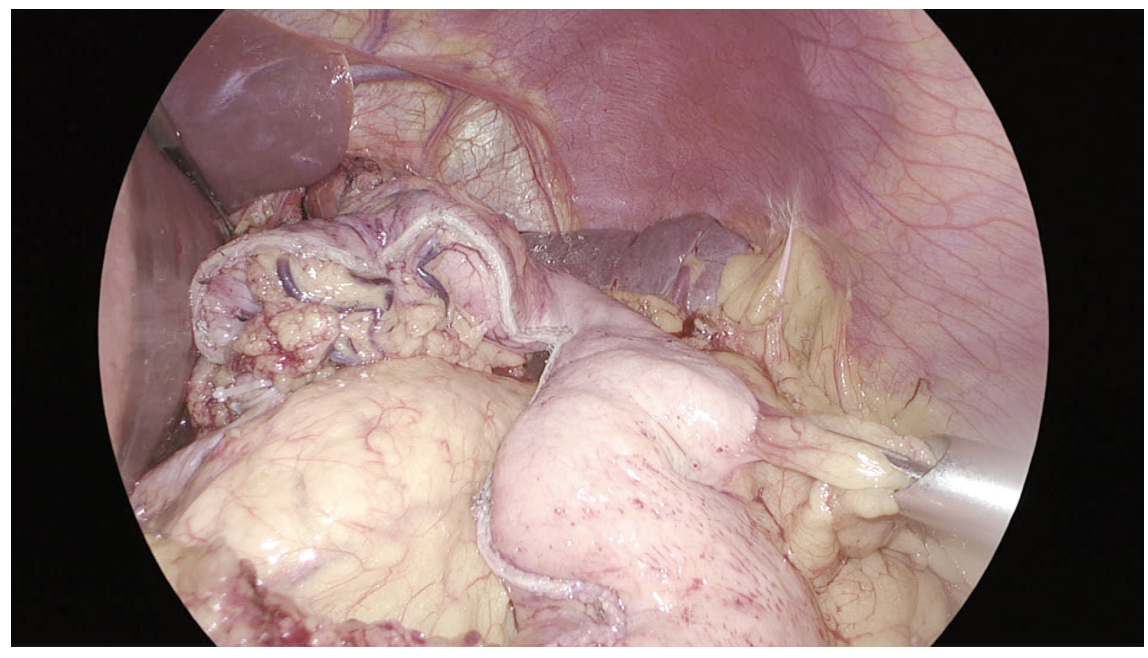

Figure 4. Gastric conduit creation

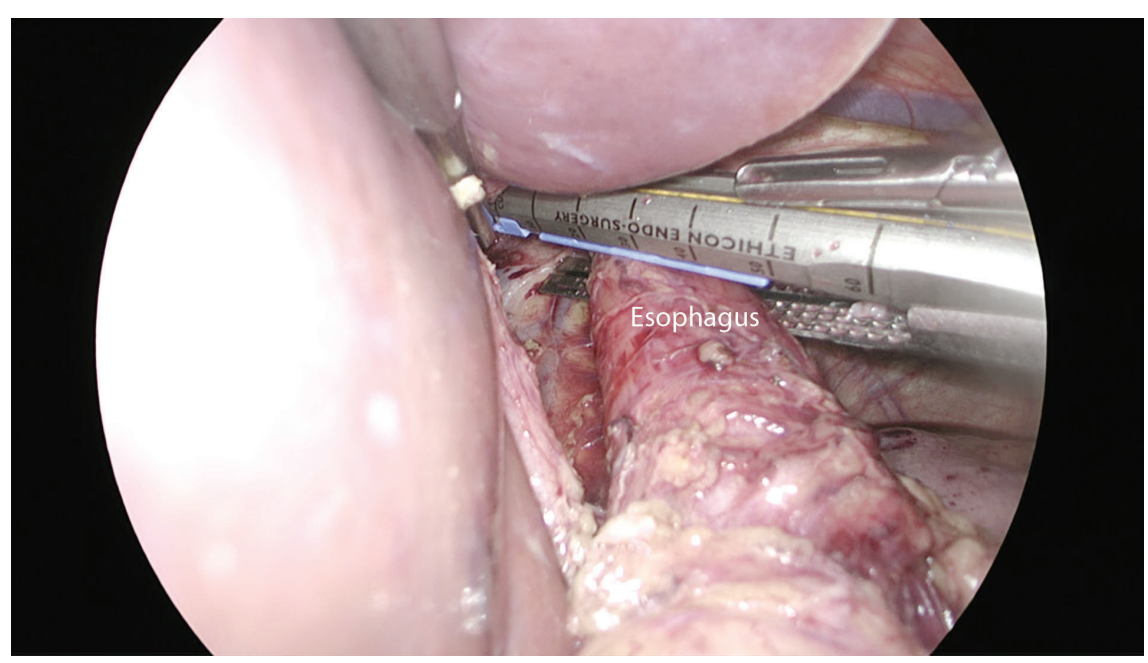

Figure 5. Transhiatal division of esophagus 


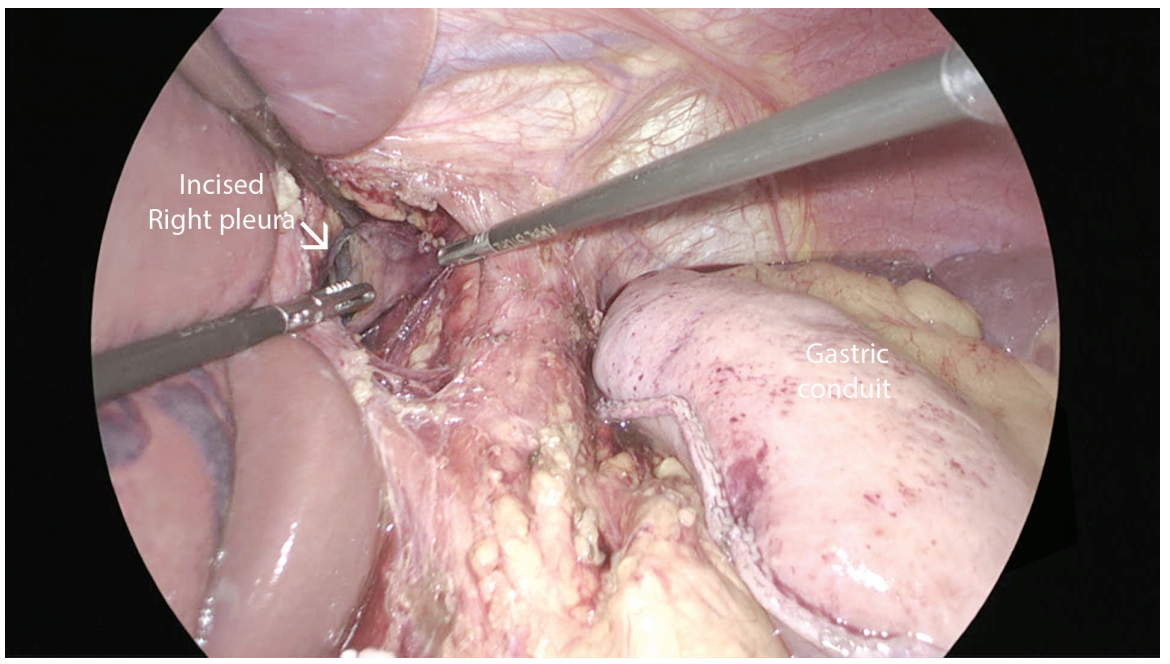

Figure 6. Placing the gastric tube in the right pleural cavity, to prevent slippage into the abdominal cavity

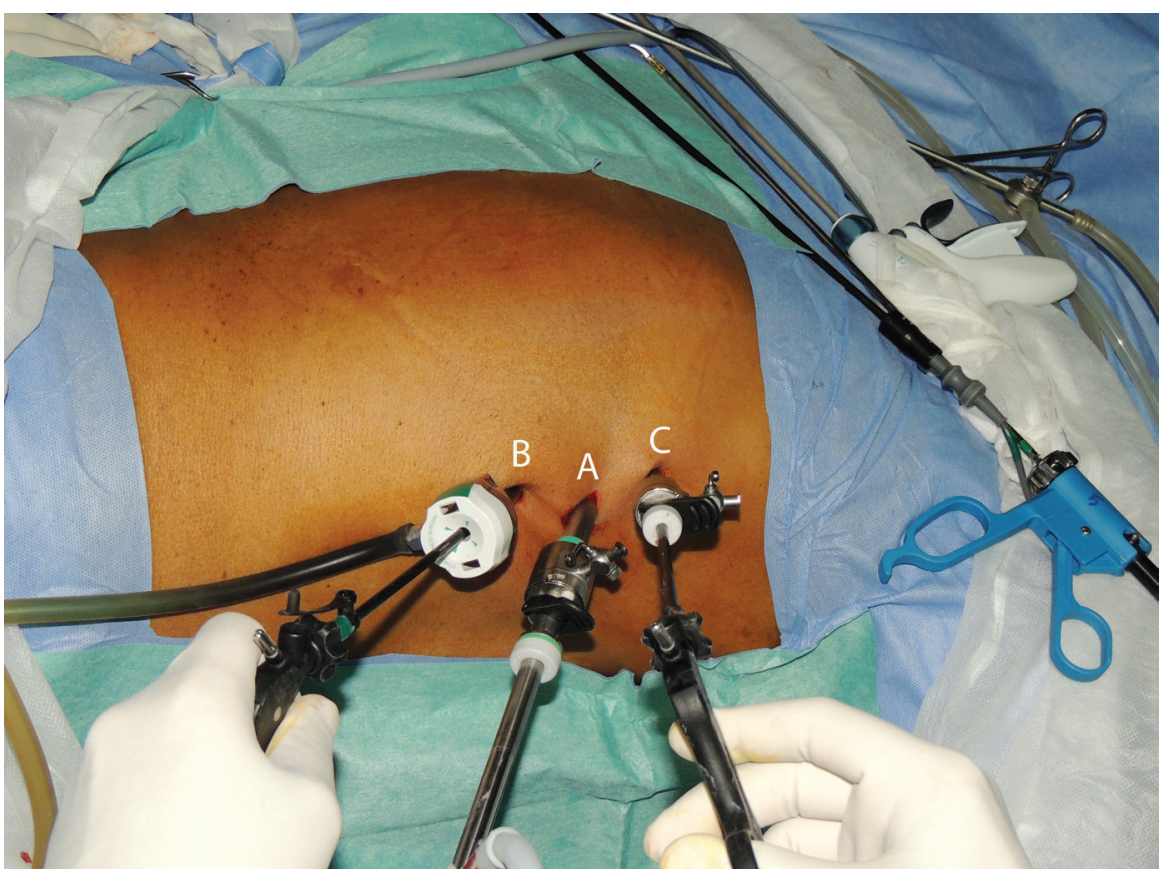

Figure 7. Thoracoscopic port position. A: 7th intercostal space below the inferior angle of the scapula for camera: $10 \mathrm{~mm}$; B: 9 th intercostal space $7 \mathrm{~cm}$ away from the spinous process for left hand working port: $5 \mathrm{~mm}$; C: 5 th intercostal space $7 \mathrm{~cm}$ away from the spinous process for right hand working port: $5 \mathrm{~mm}$

\section{Stage II: Thoracic phase}

In the second phase, thoracoscopic esophageal mobilization, resection, and the anastomosis are done in semi-prone position with the same single-lumen endotracheal tube intubation. Ports [Figure 7].

Access to the thoracic cavity can be gained by either placing a veress needle followed by port insertion or through direct port placement using optiview trocar. Before placing initial trocar scapula to be retracted medially and superiorly with the help of an assistant to provide easy access to the thoracic cavity (We prefer trocar placement under direct vision because in this part of the world most of the patients might have a tubercular infection associated with pleural adhesions).

After gaining access, $\mathrm{CO}_{2}$ pneumo with $8 \mathrm{mmHg}$ pressure to be maintained. The anesthetist is requested to keep the low tidal volume for a brief period to facilitate lung collapse. Inside the thoracic cavity, the gastric 


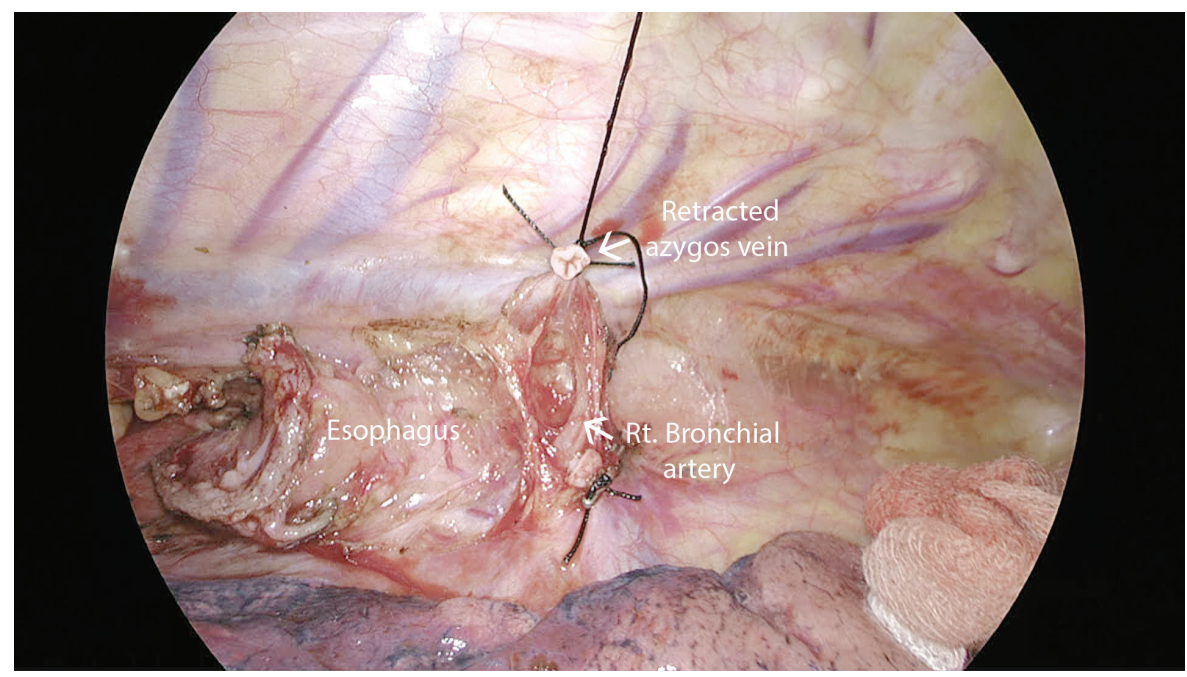

Figure 8. Exposure after retraction of the divided azygous vein

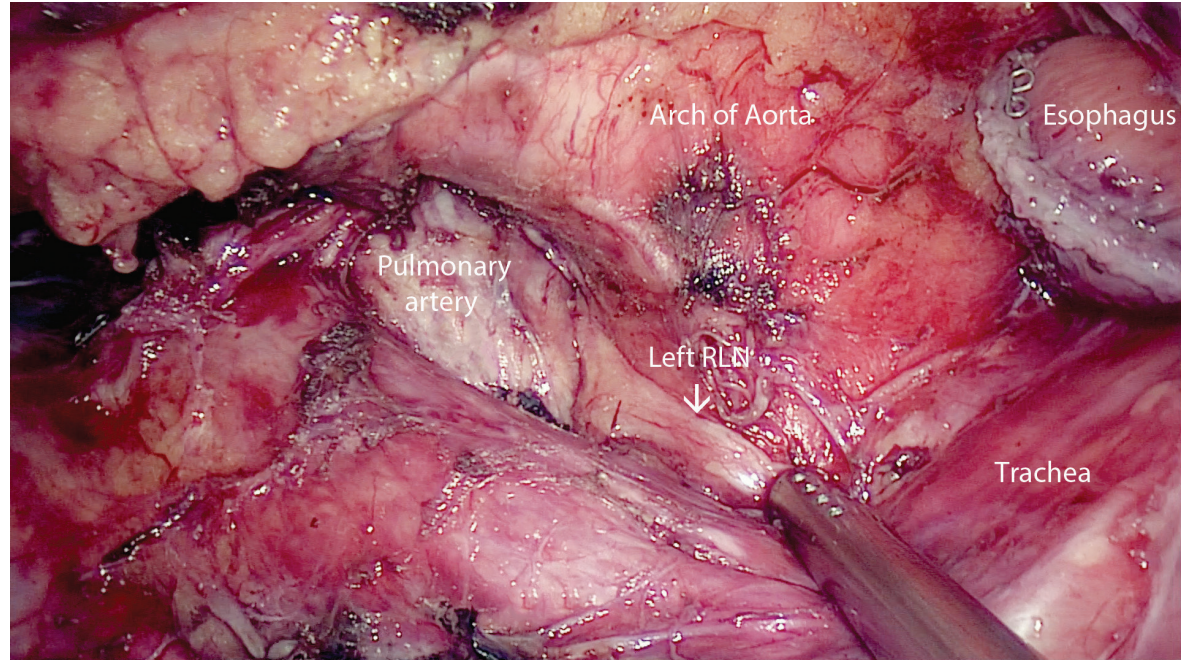

Figure 9. Subcarinal lymph node dissection

conduit to be visualized and pulled up to check for adequacy of the length of the conduit. Mediastinal pleura incised, Azygous vein is skeletonized at the level of the azygous arch, Azygous vein is doubly ligated with silk no two sutures, and one suture towards the vertebral end is left long to help in retraction of the vein during dissection of aortopulmonary window [Figure 8]. The esophagus is mobilized proximally till the subcarinal level (usually 5-6 cm above the transected end to achieve adequate proximal margin), and nodal lymph dissection is done [Figure 9]. We perform standard two-field lymphadenectomy; thoracic duct is not excised in all the cases, except in cases where the patient weight is below $35 \mathrm{~kg}$.

Proximally with adequate clearance esophagus is divided using endo GIA stapler. After proximal esophageal division, four full-thickness (adventitia to the mucosa) sutures are placed anteriorly on both the sides and posteriorly to prevent esophageal mucosal retraction [Figure 10]. The gastric conduit is pulled closer, and the esophagogastric anastomosis is performed [Figure 11].

Esophagogastric anastomosis: This is accomplished in three ways: (1) End to end/side hand-sewn anastomosis; (2) End to side fully mechanical anastomosis-circular stapler; (3) Side to side fully mechanical anastomosis-linear cutter stapler. End to end/side hand-sewn anastomosis: The two ends are approximated 


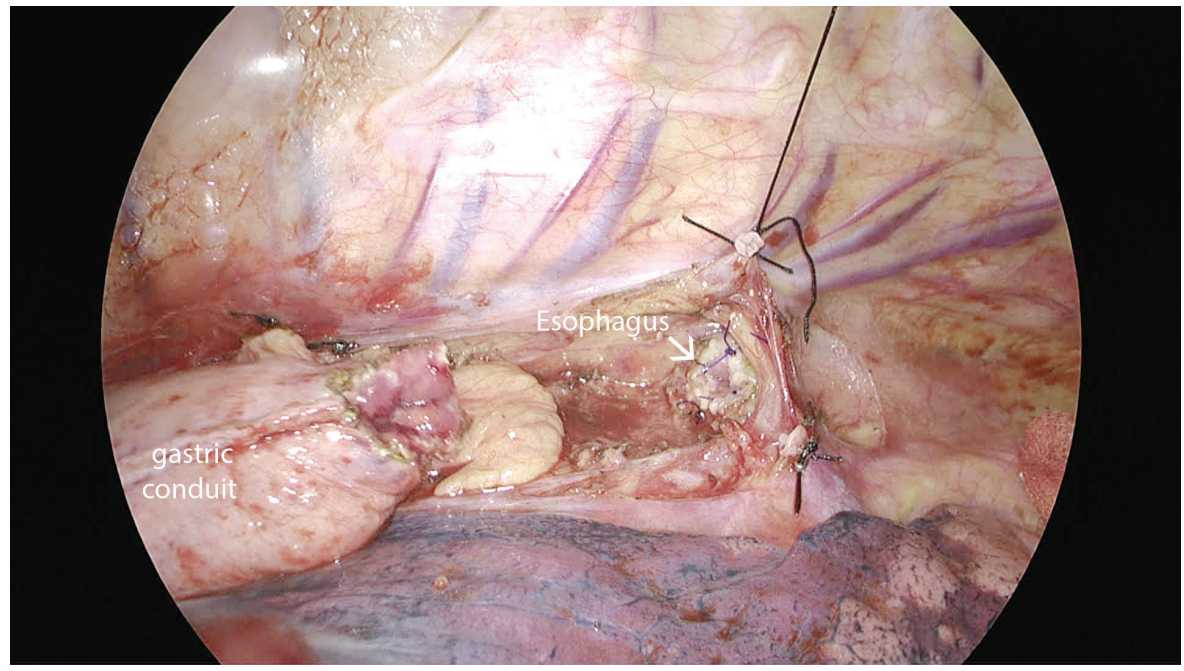

Figure 10. Proximal esophagus full-thickness sutures preventing mucosal retraction

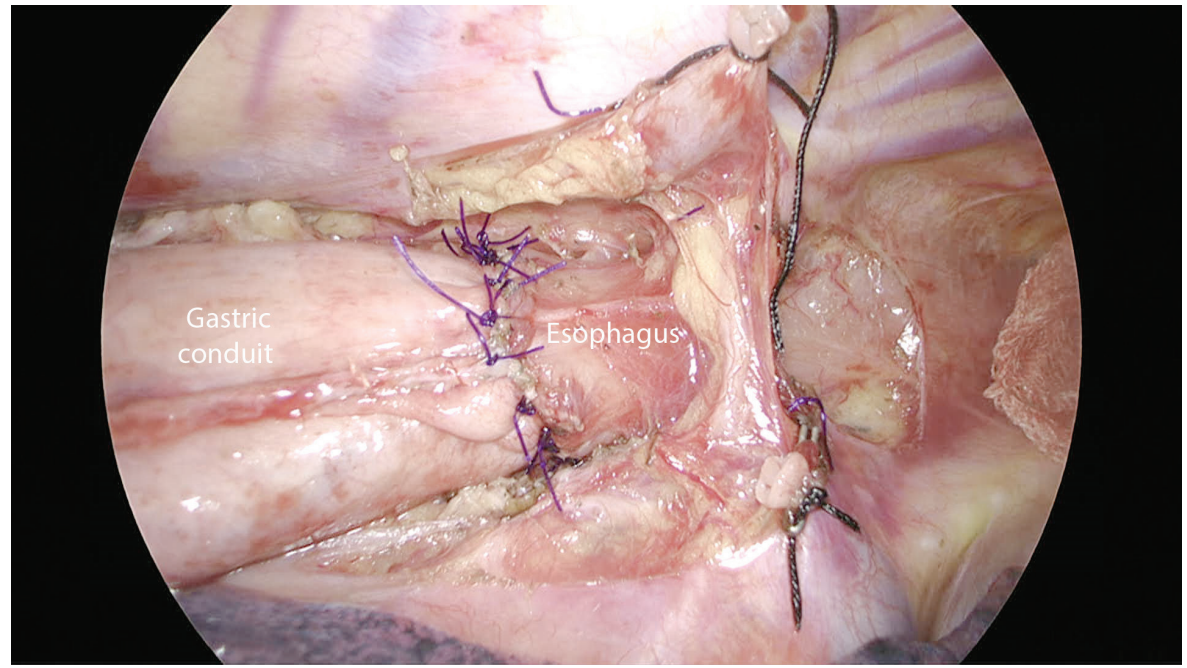

Figure 11. End to end esophagogastric anastomosis

in two layers interrupted sutures using 2-0 PDS (polydioxanone) (@ Ethicon US, LLC). Side to side semimechanical anastomosis: Using linear staplers, intrathoracic side to side esophagogastric anastomosis done. The stapler entry wound to be closed with 2-0 PDS. End to side fully mechanical anastomosis: When gastric conduit width is more, stapling technique is preferred, and narrower tube hand-sewn anastomosis is done.

The linear stapling technique $12 \mathrm{~mm}$ trocar is placed in the 11/12th intercostal space for stapler insertion [Figure 12]. The trocar is placed at the angle of the rib. Using monopolar cautery, enterotomy is made on the staple line of the stomach, and similarly, entry is made at the stapled edge of the esophagus. When the esophagus is divided without a staple, then one of the jaws may be placed directly into the lumen and side to side anastomosis is done by linear anastomosis. The anterior anastomosis is done by intrathoracic handsewn suturing technique or a stapler in triangulation manner.

\section{Intra-corporeal anastomosis by hand suturing technique}

Ends of the gastric conduit and the esophagus are trimmed, and end to end anastomosis is done. 3-0 PDS with a small curved needle is used for suturing. 


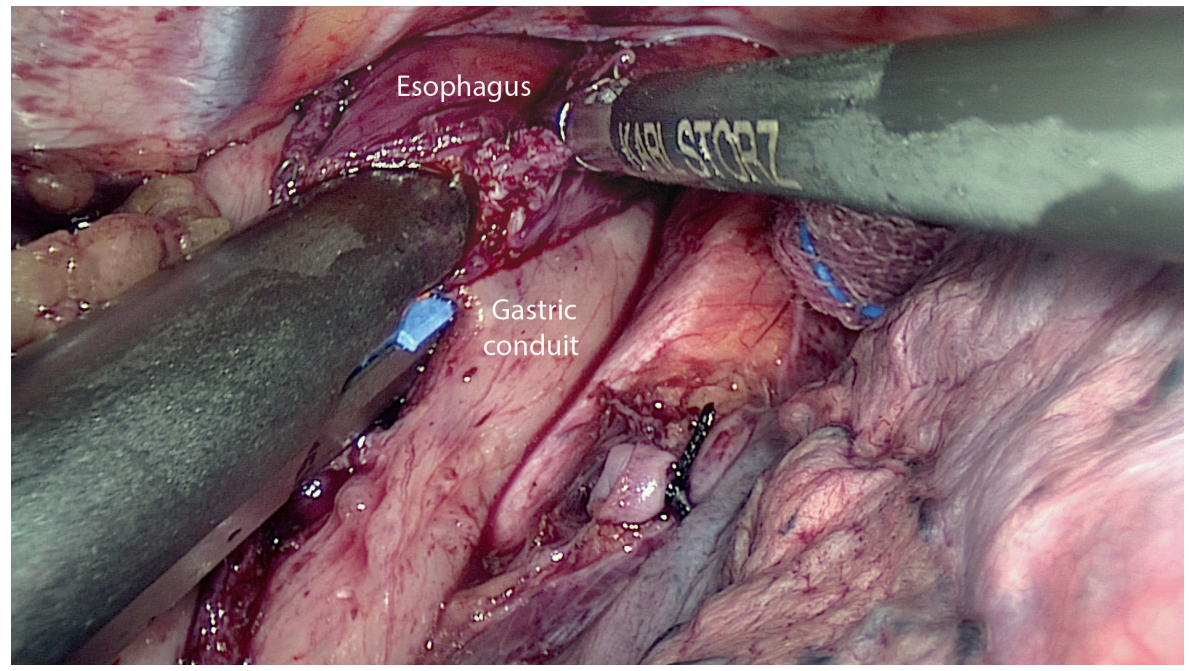

Figure 12. Esophagogastric anastomosis using linear stapler

\section{Circular Stapling technique}

Proximal Esophagus is transected using 60mm blue cartridge, $5 \mathrm{~cm}$ proximal to azygos arch in an oblique manner. Peroral anvil [Orvil ${ }^{\mathrm{TM}}$ (Medtronic, Covidien, MN, USA)] is passed orally, and a small opening is made at one edge of the stapled line and anvil is positioned in the divided end of the esophagus. Gastric conduit is advanced to the apex of the thoracic cavity, and an opening is made in the staple line on the lesser curvature. Then a 3-4 cm incision is formed on the right thoracic cavity at the level of 11th rib for entry of the circular stapler. $25 \mathrm{~mm}$ circular stapler is introduced into the thoracic cavity with the protective plastic sleeve [Figure 13]. Head of the stapler is introduced into gastric conduit and pin is pierced on to the greater curvature side and docked to the anvil and fired [Figure 14]. Stapler entry on the gastric tube is closed by intracorporeal sutures using 20 PDS [Figure 15].

In few cases of SCC of GE junction, a circular stapler is used to achieve intra thoracic anastomosis close to the thoracic inlet.

Feeding access in all our patients is by a Naso-Jejunal tube placed intraoperatively while constructing the anastomosis. Feeding jejunostomy is not routinely practiced in our patients. An-intercostal drainage is placed in the right pleural cavity.

\section{Postoperative period}

We practice the technique of early extubation in the immediate postoperative period. All the patients are shifted to ICU for observation and supportive care in the early postoperative period. Oral gastrograffin study to check the functionality of gastric conduit is performed on POD 2 following which oral liquids are initiated. CT scan with oral contrast is performed in patients with high suspicion of the leak.

\section{RESULTS}

In 11 years, we had performed 532 cases of minimally invasive esophagectomies for both malignant and benign etiologies. Out of which 143 Cases were of ILE [Table 1]. The mean age of patients was $64.4 \pm 10.86$ years, and male to female ratio was 3:1. Out of these cases, 139 (97.20\%) were performed for malignancy and $4(2.79 \%)$ for benign cases, which include peptic stricture, sigmoid esophagus. The mean operative time was $457.97 \pm 79.35 \mathrm{~min}$. The mean blood loss was $138.08 \pm 29.3 \mathrm{~mL}$. Out of these cases, the handsewn anastomosis was performed in $72(50.34 \%)$, circular stapler anastomosis in $46(32.16 \%)$ linear stapled 


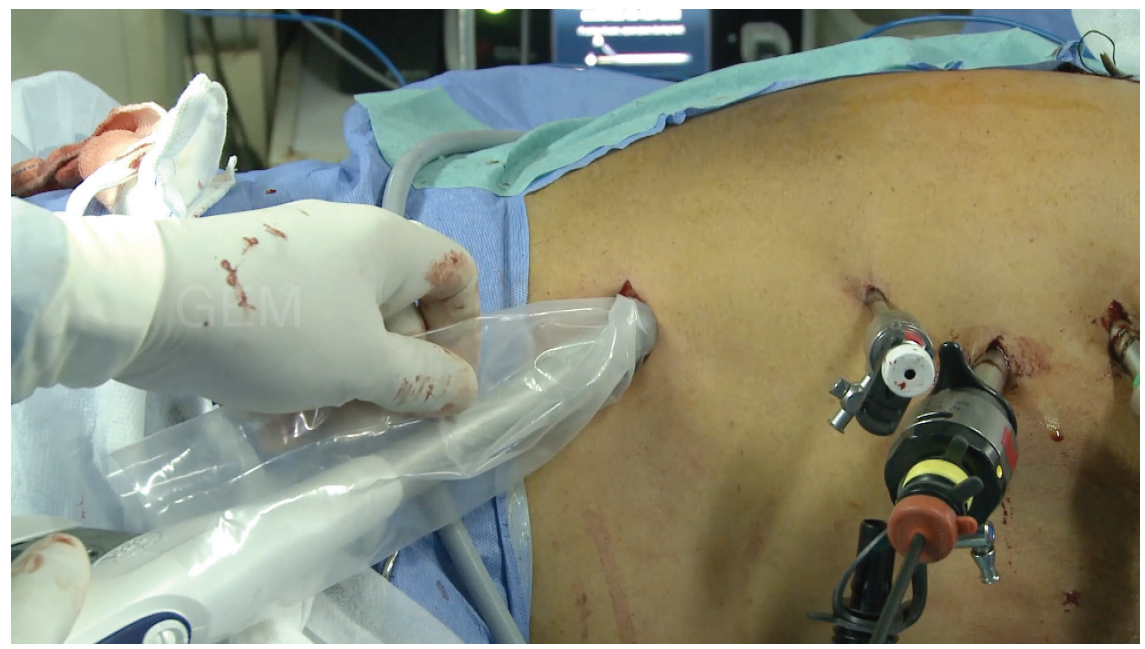

Figure 13. Transthoracic insertion of circular stapler

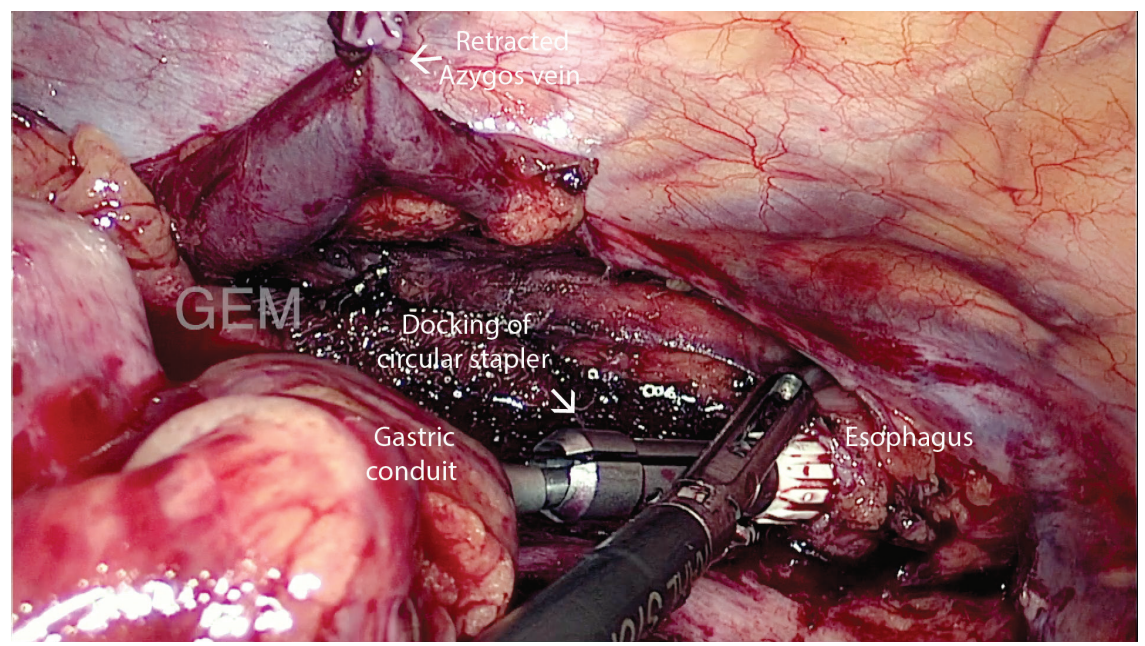

Figure 14. Docking of circular stapler

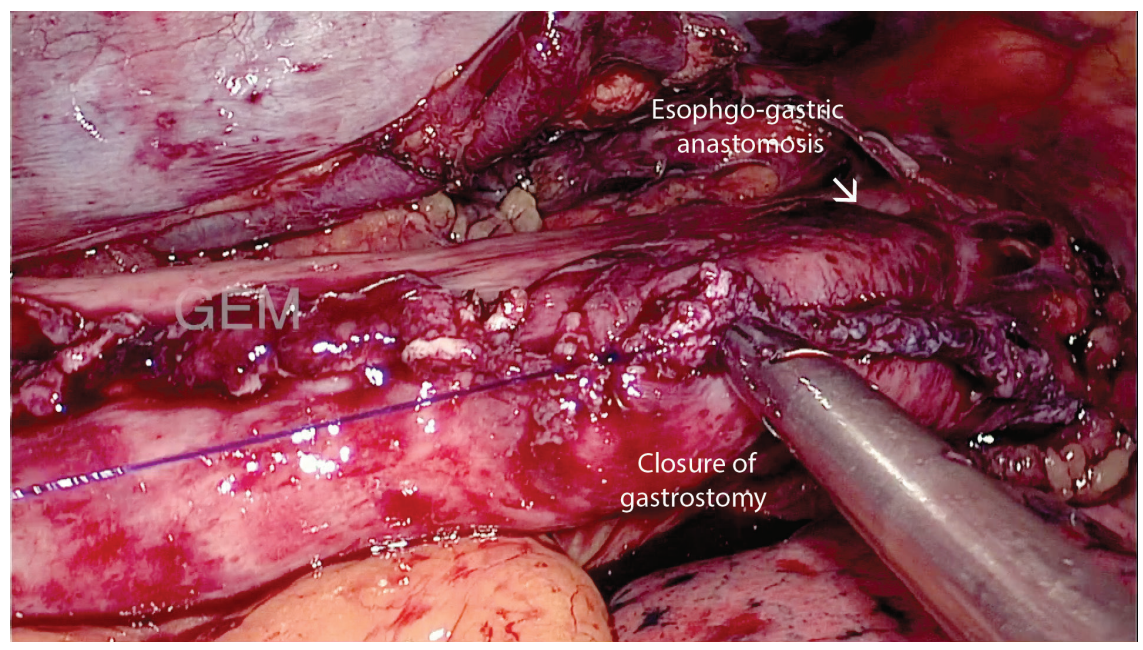

Figure 15. Closure of the gastrotomy wound after circular stapler 
Table 1. Demographic, intraoperative, postoperative parameters

\begin{tabular}{|c|c|c|}
\hline Sr. No. & Parameter & Value (Mean \pm Standard Deviation) \\
\hline (1) & Age (in years) & $64.4 \pm 10.86$ \\
\hline (2) & $\operatorname{Sex}(M: F)$ & $3: 1$ \\
\hline (3) & $\begin{array}{l}\text { Etiology } \\
\text { (a) Malignant } \\
\text { (b) Non-malignant }\end{array}$ & $\begin{array}{l}\text { Total-143 } \\
139(97.20 \%) \\
4(2.79 \%)\end{array}$ \\
\hline (4) & $\begin{array}{l}\text { (a) Thoraco-laparoscopy } \\
\text { (b) Robotic }\end{array}$ & $\begin{array}{l}138(96.50 \%) \\
5(3.49 \%)\end{array}$ \\
\hline (5) & Duration (in mins) & $457.97 \pm 79.35$ \\
\hline (6) & Blood loss (in ml) & $138.08 \pm 29.3$ \\
\hline (7) & Lymph nodes retrieved & $22.68 \pm 9.49$ \\
\hline (8) & $\begin{array}{l}\text { Anastomosis } \\
\text { (a) Circular } \\
\text { (b) Linear stapler } \\
\text { (c) Hand sewn }\end{array}$ & $\begin{array}{l}46(32.16 \%) \\
25(17.48 \%) \\
72(50.34 \%)\end{array}$ \\
\hline (9) & ICU stay (in days) & $4.68 \pm 3.95$ \\
\hline (10) & Duration of hospital stay (in days) & $13.48 \pm 7.43$ \\
\hline (11) & $\begin{array}{l}\text { Histology (n-139) } \\
\text { (a) Adeno carcinoma } \\
\text { (b) Squamous cell carcinoma }\end{array}$ & $\begin{array}{l}121(87.05 \%) \\
18(12.94 \%)\end{array}$ \\
\hline (12) & $\begin{array}{l}\text { T Staging }(n-139) \\
\text { (a) T2 } \\
\text { (b) T3 } \\
\text { (c) T4 }\end{array}$ & $\begin{array}{l}56(40.28 \%) \\
77(55.39 \%) \\
6(4.31 \%)\end{array}$ \\
\hline (13) & $\begin{array}{l}\text { Complications } \\
\text { (a) Pneumonia } \\
\text { (b) RLN injury } \\
\text { (c) Chyle leak } \\
\text { (d) Anastomotic Leak } \\
\text { (e) Anastomotic stricture }\end{array}$ & $\begin{array}{l}25.17 \% \\
12(8.39 \%) \\
2(1.39 \%)-1 \text { required tracheostomy } \\
1(0.69 \%) \\
3(2.09 \%) \\
18(12.58 \%)\end{array}$ \\
\hline (14) & $\begin{array}{l}\text { Re-intervention } \\
\text { (a) Endoscopic } \\
\text { (b) Thoracoscopy }\end{array}$ & $\begin{array}{l}3(2.09 \%) \text { (combined endoscopic and } \\
\text { thoracoscopic procedure done) } \\
3(2.09 \%) \\
3(2.09 \%)\end{array}$ \\
\hline$(15)$ & 30-day mortality & $1(0.69 \%)$ \\
\hline
\end{tabular}

anastomosis in $25(17.48 \%)$ of cases. The mean lymph node retrieval rate was $22.68 \pm 9.49$ nodes. The average ICU stay in the postoperative period was $4.68 \pm 3.95$ days, and overall hospital stay was $13.48 \pm$ 7.43 days. Among malignant cases (139), adenocarcinoma in 121 (87.05\%), SCC in 18 (12.94\%). Among these cases T2, lesions in $56(40.28 \%)$, T3 lesions in 77 (55.39\%), T4 lesions in $6(4.31 \%)$ The overall complication rate was $25.17 \%$ (pneumonia - 8.39\%, RLN (recurrent laryngeal nerve) injury in $1.39 \%$, anastomotic leak in $2.09 \%$, chyle leak in $0.69 \%$ ). Overall anastomotic stricture rate is $12.58 \%$. The stricture rate was more in linear stapler technique compared to the other two. Six cases had re-intervention in the form of endoscopic procedures in $3(2.09 \%)$ and re-thoracoscopy in $3(2.09 \%)$. Laparoscopic feeding jejunostomy was done in $2 \%$ of patients who had re-intervention because of anastomotic leak. Overall 30-day mortality noted in 1 case $(0.69 \%)$.

\section{DISCUSSION}

We have been performing minimally invasive esophagectomies since $1997^{[7]}$. Since then all esophagectomies were conducted in the prone position during the thoracic phase. For cases of GE junction tumors, we performed trans hiatal esophagectomies with excellent results ${ }^{[8]}$. But later on, to achieve better proximal clearance we have opted performing thoracolaparoscopic esophagectomies. In cases of SCC of lower esophagus close to GE junction, we have performed intrathoracic anastomosis using circular stapler close to the level of the thoracic inlet. Throughout 11 years, the rate of performing intrathoracic anastomosis improved year by year because of change in the incidence of adenocarcinoma and experience in the technique of intrathoracic anastomosis. For lesions requiring division above the level of the azygous arch, 
we performed the circular anastomosis. Till the level of the azygous arch, we have completed hand sewn or linear staple anastomosis. Presently Our preferred technique of anastomosis is circular stapler technique if the level of the anastomosis is above the level of azygous arch and at the level of azygous or below the azygous arch hand-sewn technique because of better ergonomics. In robotic cases because of ease of suturing, we prefer hand-sewn anastomosis in all the circumstances.

Initial reports of totally endoscopic ILE was by Watson et al. ${ }^{[9]}$ who described, the technique of handassisted laparoscopy for gastric mobilization and a right thoracoscopy for esophageal dissection and anastomosis in two patients.

One of the potential advantages of the minimally invasive trans-thoracic approach is better exposure and improved lymph node dissection in the mediastinum, associated with low morbidity and mortality. The reported rate of peri-operative complications, including anastomotic leak, pneumonia, and recurrent nerve injury, was quite low ${ }^{[10]}$.

Baranov et al. ${ }^{[11]}$ in their study of 446 patients of minimally invasive ILE, 357 patients were younger than 75 years (younger group) and 89 patients were aged 75 years and older (elderly group) found that regarding severe complications there was no significant difference between the younger and the elderly group (35.9\% in the younger group versus $43.8 \%$ in the elderly group, $P=0.421$ ) and the 30 days mortality was 30 -day mortality was $2.8 \%$ in the younger group versus $2.2 \%$ in the elderly group $(P=0.889)$. They have concluded that minimally invasive ILE can be safely performed in selected patients aged $\geq 75$ years, without increasing severe complications or decreasing survival.

In a recent systemic review and meta-analysis by Deng et al. ${ }^{[12]}$ in 2018 Comparing short-term outcomes between minimally invasive McKeown esophagectomy (MIME) and minimally Ivor Lewis esophagectomy (MILE) for esophageal or junctional cancer found that MIME was associated with more blood loss, longer operating time, and longer hospital stay than MILE. Pulmonary complications (OR $=1.96,95 \% \mathrm{CI}: 1.28$ 3.00) as well as total anastomotic leak ( $\mathrm{OR}=2.55,95 \% \mathrm{CI}$ : $1.40-4.63)$, stricture ( $\mathrm{OR}=2.07,95 \% \mathrm{CI}$ : 1.05-4.07), and vocal cord injury/palsy (OR $=5.62,95 \% \mathrm{CI}$ : 3.46-9.14) were significantly higher in MIME compared to MILE $^{[12]}$. In TIME trial, long term results, after three years follow-up, found no differences in diseasefree $(37.3 \%$ vs. $42.9 \%, P=0.602)$ and overall $(41.2 \%$ vs. $42.9 \%, P=0.633) 3$-year survival between open esophagectomy and minimally invasive esophagectomy ${ }^{[13]}$. In their study they also found that minimally invasive esophagectomy in post neoadjuvant therapy compare to upfront surgery showed no difference in resection rates and concluded that minimally invasive surgery might be safely attempted in post neoadjuvant cases which were considered as a contraindication due to radiation fibrosis ${ }^{[14]}$.

In our study, the anastomotic leak is $2.09 \%$ compared to $4.7 \%$ shown in the meta-analysis of various studies $^{[15]}$. The overall pulmonary complications in our study are $8.39 \%$ in comparison to $17.1 \%$ in minimally invasive esophagectomies, in a meta-analysis of 57 studies $^{[16]}$. The lymph node retrieval rate is $22.68 \pm 9.49$ in comparison to $22 \pm 10$ in a propensity score-matched study comparing open and laparoscopic group by Rinieri et al. ${ }^{[17]}$. The length of ICU stay in our study is $4.68 \pm 3.95$ days, and length of hospital stay is $13.48 \pm 7.43$ days, in comparison to 3.6 days and 12 days in a similar stud of minimally invasive ILE by Zonča et al. ${ }^{[18]}$. The 30 day mortality rate is $0.69 \%$ in comparison to $1 \%$ shown in a systematic review by Deng et al. ${ }^{[12]}$.

In conclusion, thoracolaparoscopic esophagectomy with intrathoracic Ivor Lewis anastomosis is an excellent option for selected patients, in experienced hands. 


\section{DECLARATIONS}

\section{Authors' contributions}

Data acquisition, conceptualization, manuscript writing, and critical revision of the manuscript: Parthasarathi R, Gupta GR, Sabnis SC, Raj PP, Senthilnathan P, Rajapandian S, Palanivelu C.

All authors contributed equally for the manuscript.

\section{Availability of data and materials}

Not applicable.

\section{Financial support and sponsorship}

None.

\section{Conflicts of interest}

All authors declared that there are no conflicts of interest.

\section{Ethical approval and consent to participate}

In-hospital GEM ethic's committee has approved this study. The ethical committee has approved a waiver of consent given the retrospective nature of the study. All efforts are made to keep the individual patient's identity anonymous.

\section{Consent for publication}

Not applicable.

\section{Copyright}

(c) The Author(s) 2019.

\section{REFERENCES}

1. Bray F, Ferlay J, Soerjomataram I, Siegel RL, Torre LA, et al. Global Cancer Statistics 2018: GLOBOCAN Estimates of Incidence and Mortality Worldwide for 36 Cancers in 185 Countries. CA-Cancer J Clin 2018;68:394-424.

2. Edgren G, Adami HO, Weiderpass E, Nyrén O. A global assessment of the oesophageal adenocarcinoma epidemic. Gut 2013;62:140614.

3. Bollschweiler E, Wolfgarten E, Gutschow C, Hölscher AH. Demographic variations in the rising incidence of esophageal adenocarcinoma in white males. Cancer 2001;92:549-55.

4. Hashimoto T, Kurokawa Y, Mori M, Doki Y. Surgical Treatment of Gastroesophageal Junction Cancer. J Gastric Cancer 2018;18:20917.

5. Lewis I. The surgical treatment of carcinoma of the esophagus; with special reference to a new operation for growths of the middle third. Br J Surg 1946;34:18-31.

6. Huang L, Onaitis M. Minimally invasive and robotic Ivor Lewis esophagectomy. J Thorac Dis 2014;6:S314-21.

7. Palanivelu C, Prakash A, Senthilkumar R, Senthilnathan P, Parthasarathi R, et al. Minimally invasive esophagectomy: thoracoscopic mobilization of the esophagus and mediastinal lymphadenectomy in prone position-experience of 130 patients. J Am Coll Surg 2006;203:7-16.

8. Palanivelu C, Prakash A, Parthasarathi R, Senthilkumar R, Senthilnathan PR, et al. Laparoscopic esophagogastrectomy without thoracic or cervical access for adenocarcinoma of the gastroesophageal junction: an Indian experience from a tertiary center. Surg Endosc 2007;21:16-20.

9. Watson DI, Davies N, Jamieson GG. Totally endoscopic Ivor Lewis esophagectomy. Surg Endosc 1999;13:293-7.

10. Bizekis C, Kent MS, Luketich JD, Buenaventura PO, Landreneau RJ, et al. Initial experience with minimally invasive Ivor Lewis esophagectomy. Ann Thorac Surg 2006;82:402-6.

11. Baranov NS, van Workum F, van der Maas J, Kouwenhoven E, van Det M, et al. The Influence of Age on Complications and Overall Survival After Ivor Lewis Totally Minimally Invasive Esophagectomy. J Gastrointest Surg 2019;23:1293-300.

12. Deng J, Su Q, Ren Z, Wen J, Xue Z, et al. Comparison of short-term outcomes between minimally invasive McKeown and Ivor Lewis esophagectomy for esophageal or junctional cancer: a systematic review and meta-analysis. Onco Targets Ther 2018;11:6057-69.

13. Straatman J, van der WN, Cuesta MA, Daams F, Roig GS, et al. Minimally Invasive Versus Open Esophageal Resection: Three-year Follow-up of the Previously Reported Randomized Controlled Trial: the TIME Trial. Ann Surg 2017;266:232-6. 
14. Tan L, Tang H. Oncological outcomes of the TIME trial in esophageal cancer: is it the era of minimally invasive esophagectomy? Ann Transl Med 2018;6:85.

15. van Workum F, Berkelmans GH, Klarenbeek BR, Nieuwenhuijzen GAP, Luyer MDP, et al. McKeown or Ivor Lewis totally minimally invasive esophagectomy for cancer of the esophagus and gastroesophageal junction: systematic review and meta-analysis. J Thorac Dis 2017;9:S826-33.

16. Yibulayin W, Abulizi S, Lv H, Sun W. Minimally invasive oesophagectomy versus open esophagectomy for resectable esophageal cancer: a meta-analysis. World J Surg Oncol 2016;14:304.

17. Rinieri P, Ouattara M, Brioude G, Loundou A, de Lesquen H, et al. Long-term outcome of open versus hybrid minimally invasive IvorLewis oesophagectomy: a propensity score matched study. Eur J Cardiothorac Surg 2017;51:223-9.

18. Zonča P, Peteja M, Richter V, Vávra P, Ostruszka P, et al. Complete minimally invasive Ivor-Lewis esophageal resection. Rozhl Chir 2017;96:114-9. 